\title{
High Prevalence of Hypovitaminosis D in Postmenopausal Women with Type 2 Diabetes Mellitus
}

\section{Ivan Raška Jr., Mária Rašková, Vít Zikán, Jan Škrha}

$3^{\text {rd }}$ Department of Medicine - Department of Endocrinology and Metabolism, First Faculty of Medicine, Charles University in Prague and General University Hospital in Prague, Prague, Czech Republic

Received November 6, 2015; Accepted February 24, 2016.

Key words: Type 2 diabetes mellitus - Vitamin D - Parathyroid hormone Hypovitaminosis D - Body composition

Abstract: The link between vitamin $D$ and type 2 diabetes mellitus (T2DM) is intensively studied. This study aims to define the serum concentration of 25-hydroxyvitamin D (25-OH D) and to investigate the relationship between 25-OH D status, glycated hemoglobin (HbA1c) and body composition in postmenopausal women with T2DM and in non-diabetic controls. In this crosssectional study, 75 women with T2DM and 32 control subjects were selected. Serum 25-OH D, intact parathyroid hormone (PTH), calcium, fasting glucose and $\mathrm{HbA1c}$, were measured. The mean 25-OH D level was $21.4 \pm 11.4 \mathrm{ng} / \mathrm{ml}$ (range $4.1-50.7 \mathrm{ng} / \mathrm{ml}$ ) in diabetic women and $30.3 \pm 9.4 \mathrm{ng} / \mathrm{ml}$ (range 10.8-54.2 ng/ml) in control group $(p<0.001)$. The prevalence of hypovitaminosis $D(<30 \mathrm{ng} / \mathrm{ml})$ was higher in vitamin $\mathrm{D}_{3}$ non-supplemented T2DM women (89\% vs. $63 \%$ controls); the difference diminished in vitamin $D_{3}$ (500-1000 IU per day) supplemented subgroups (45\% diabetics vs. $42 \%$ controls). In T2DM women, $25-\mathrm{OH}$ D levels were not associated to $\mathrm{HbA} 1 \mathrm{c}$, duration of diabetes, fasting glucose and PTH levels, however, 25-OH D levels negatively associated with body mass index $(p=0.011)$, total body fat mass $(p=0.005)$ and total body lean mass $(p=0.004)$. The prevalence

This study was supported by IGA Ministry of Health of the Czech Republic No. NT 11335-6/2010.

Mailing Address: Ivan Raška Jr., MD., PhD., $3^{\text {rd }}$ Department of Medicine Department of Endocrinology and Metabolism, First Faculty of Medicine, Charles University in Prague and General University Hospital in Prague, U Nemocnice 1, 12808 Prague 2, Czech Republic; e-mail: Ivan.Raska@vfn.cz 
of hypovitaminosis $D$ is higher in non-supplemented postmenopausal women with T2DM than in non-diabetic controls ( $89 \%$ vs. $63 \%)$. Obesity is a risk factor for vitamin $D$ insufficiency in T2DM postmenopausal women. Further studies evaluating relationships between fat, muscle, bone and vitamin D metabolism in T2DM patients are warranted.

\section{Introduction}

The effect of vitamin D on bone tissue and calcium-phosphate homeostasis is well known. Vitamin D deficiency may lead to osteoporosis, osteomalacia and is associated with diffuse muscle pain and muscle weakness and increased risk of falls (Plotnikoff and Quigley, 2003; Bischoff-Ferrari et al., 2004). In addition, vitamin D deficiency has been linked to a broadening field of health problems including several types of cancer and autoimmune or metabolic diseases such as type 1 diabetes mellitus and type 2 diabetes mellitus (Wolden-Kirk et al., 2011).

Type 2 diabetes mellitus (T2DM) is a progressive chronic disease recognized by both insulin resistance and $\beta$-cell dysfunction (Badawi et al., 2014). There is evidence that patients with T2DM have an increased risk of fractures (Janghorbani et al., 2007; Martinez-Laguna et al., 2015). However, despite the increased fracture risk, bone mineral density (BMD) is generally higher in patients with T2DM (Vestergaard, 2007). Additional skeletal material aspects, such as accumulation of advanced glycation end products (AGEs) that are undetectable by BMD may contribute to diabetic skeletal fragility. As the incidence of T2DM continues to increase, it is necessary to understand what stands behind the increased fracture risk in these patients.

The reported prevalence of vitamin $D$ deficiency or insufficiency in patients with T2DM varies from 70 to $90 \%$ (Tahrani et al., 2010; Miñambres et al., 2014; Muscogiuri et al., 2016) and depends on the threshold used to define vitamin D deficiency or insufficiency. The risk factors for vitamin $D$ insufficiency in T2DM include poor dietary habits, lack of sun exposure, obesity, renal impairment and genetic predisposition (Penckofer et al., 2008).

The underlying mechanism explaining the association between vitamin $D$ deficiency and T2DM is not fully understood. Several explanations have been proposed. Norman et al. (1980) identified expression of the vitamin D receptor (VDR) in rat pancreatic cells and demonstrated that a deficiency of vitamin $\mathrm{D}$ inhibits the production of insulin. In addition, the deficiency of vitamin $D$ has been implicated as the predictive factor for the occurrence of diabetes (Scragg et al., 2004) and increasing the vitamin D concentration in the blood has a positive effect on maintaining glucose homeostasis by increasing insulin sensitivity (Delvin, 2011).

The aim of this study is to define the serum 25-hydroxyvitamin $\mathrm{D}(25-\mathrm{OH} \mathrm{D})$ levels and to investigate the relationship between 25-OH D status, glycated hemoglobin and body composition indices in postmenopausal women with T2DM and non-diabetic controls. 


\section{Methods}

Postmenopausal women with T2DM on anti-diabetic medication or newly detected T2DM, who attended a preventive bone mineral density (BMD) measurement, were considered for the study. The study duration was from October 2012 till October 2013. Exclusion criteria for patients were abnormal serum calcium level, serum creatinine level $>110 \mu \mathrm{mol} / \mathrm{l}$, estimated Glomerular Filtration Rate (eGFR) $<1 \mathrm{ml} / \mathrm{s} / 1.73 \mathrm{~m}^{2}$ and proteinuria, diseases other than osteoporosis and T2DM that would interfere with bone metabolism such as primary hyperparathyroidism, liver disease, malabsorption, medical history of diabetic nephropathy; or use of any other medication affecting bone metabolism within the 3 years prior the selection, such as bisphosphonates, raloxifene, strontium ranelate, fluoride, glucocorticoids, thiazolidinedions, hormone replacement therapy or vitamin $D_{3}$ supplements (in a higher dose than $1000 \mathrm{lU}$ per day). A total of 75 postmenopausal women with T2DM (mean age $66 \pm 8.5$ years) were eligible for the analysis. $A$ total of 20 patients were supplemented with a low dose of vitamin $D_{3}$ (oral supplementation of vitamin $D_{3}$ with 500-1000 IU per day), 55 patients did not take any vitamin $D_{3}$ supplements. The majority of T2DM patients were treated by metformin $(n=35)$; 18 patients were treated by combination of metformin with gliptins, sulfonylurea derivatives or insulin; 4 patients were taking sulfonylurea derivatives, 2 patients were treated by insulin and 16 patients with newly detected T2DM were without T2DM treatment.

The control group included postmenopausal women without T2DM who attended a preventive bone mineral density (BMD) measurement. The same exclusion criteria were respected also for the control group. A total of 32 postmenopausal women (mean age $64.1 \pm 5.2$ years), were eligible for the analysis. A total of 12 control subjects were provided with a low dose of vitamin $D_{3}$ supplements (oral supplementation of vitamin $D_{3}$ with 500-1000 IU per day), 20 patients did not take any vitamin $D_{3}$ supplements.

The study was undertaken with the understanding and written consent of each subject, with the approval of the Ethics Committee of the General University Hospital, and within compliance of the National Legislation and the Code of Ethical Principles for Medical Research Involving Human Subjects of the World Medical Association (Declaration of Helsinki).

\section{Bone mineral density measurement}

The BMD was determined using a dual energy $X$-ray absorptiometry (DXA) densitometer (Discovery A, Hologic, Inc., MA, USA, Software vision: Apex 3.0). BMD was measured at the lumbar spine (L1-L4), as well as the total femur, femoral neck and the whole body in all participants. We measured bodycomposition variables from the whole body scan. 


\section{Laboratory analysis}

Routine biochemical analysis was performed with fresh samples; other aliquots were stored at $-70{ }^{\circ} \mathrm{C}$ before being analysed. The serum calcium levels were measured by standard automated analytical procedure (Modular; Roche Diagnostics, Germany). The serum concentrations of intact PTH (parathyroid hormone) and 25-OH D were measured using electrochemiluminescence-based immunoanalysis (Modular; Roche Diagnostics, Germany). The serum concentrations of $25-\mathrm{OH}$ D were considered as deficient $(<10 \mathrm{ng} / \mathrm{ml})$, insufficient $(10-30 \mathrm{ng} / \mathrm{ml})$ or normal $(\geq 30 \mathrm{ng} / \mathrm{ml})$. The serum glycated hemoglobin (HbA1c) concentrations were assessed by high performance liquid chromatography. The serum fasting glucose was measured by using the enzymatic colorimetric (GOD-PAP) method.

\section{Statistical analysis}

Data were expressed by means and standard deviations if not otherwise stated. $T$-test was used for comparisons of clinical and biochemical characteristics between groups. The associations were analysed using multiple linear regression analysis. The significance was reached with a $\mathrm{p}$-value $<0.05$. Statistical analyses were made using SigmaStat statistical software v.3.5 (Jandel, San Rafael, USA).

\section{Results}

The demographic data and patients characteristics are stated in Table 1. In this cross-sectional study, T2DM postmenopausal women had significantly lower $25-\mathrm{OH} D$ levels (the mean $21.4 \pm 11.4 \mathrm{ng} / \mathrm{ml}$ ) when compared to controls (the mean $30.3 \pm 9.4 \mathrm{ng} / \mathrm{ml})(p<0.001)$ and significantly higher PTH level in T2DM patients versus controls $(p=0.026)$. Postmenopausal women with T2DM had significantly higher BMI (body mass index), total body fat mass, total body lean mass as well as total femur BMD when compared to control subjects (Table 1). The prevalence of obesity was $53 \%$ in T2DM postmenopausal women and $13 \%$ in control group.

In subjects without vitamin $D_{3}$ supplementation, the prevalence of hypovitaminosis $D(<30 \mathrm{ng} / \mathrm{ml})$ was higher in T2DM postmenopausal women than in non-diabetic controls (89\% vs. 63\%). Diabetic non-supplemented postmenopausal women had significantly lower $25-\mathrm{OH} D$ levels (the mean $18.3 \pm 9.2 \mathrm{ng} / \mathrm{ml}$ ) than the control group (the mean $27.99 \pm 8.6 \mathrm{ng} / \mathrm{ml})(\mathrm{p}<0.001)($ Table $2 \mathrm{~A})$.

In vitamin $D_{3}(500-1000 \mathrm{IU}$ per day) supplemented subjects, hypovitaminosis $D$ was seen in $45 \%$ of T2DM patients and $42 \%$ of control subjects. No statistically significant difference was found between $25-\mathrm{OH} \mathrm{D}$ levels in diabetic supplemented postmenopausal women versus supplemented control group (Table 2B).

In whole group of subjects, there was no significant difference in glycated hemoglobin, fasting glucose or duration of diabetes between T2DM postmenopausal women with hypovitaminosis $D$ and T2DM postmenopausal women with normal $25-\mathrm{OH}$ D levels. T2DM postmenopausal women with 
Table 1 - Demographic data and patients characteristics

\begin{tabular}{|c|c|c|c|}
\hline & $\begin{array}{l}\text { Postmenopausal } \\
\text { T2DM women }\end{array}$ & Controls & P-value \\
\hline$N$ & 75 & 32 & \\
\hline Age (years) & $66 \pm 8.5$ & $64.1 \pm 5.2$ & ns \\
\hline Years after menopause (years) & $16.6 \pm 8.3$ & $16.1 \pm 5.0$ & ns \\
\hline BMI $\left(\mathrm{kg} / \mathrm{m}^{2}\right)$ & $31.8 \pm 6.7$ & $25.8 \pm 4.0$ & $<0.001$ \\
\hline BMD LS (T-score) & $-0.95 \pm 0.15$ & $-1.18 \pm 0.8$ & ns \\
\hline BMD total femur (T-score) & $-0.27 \pm 1.13$ & $-0.74 \pm 0.7$ & 0.027 \\
\hline BMD femoral neck (T-score) & $-1.13 \pm 1.1$ & $-1.3 \pm 0.6$ & ns \\
\hline Whole body BMD (T-score) & $-0.56 \pm 1.5$ & $-0.52 \pm 1.2$ & ns \\
\hline Total body fat mass $(\mathrm{kg})$ & $34.8 \pm 11.1$ & $25.4 \pm 6.5$ & 0.002 \\
\hline Total body lean mass (kg) & $47.9 \pm 7.3$ & $41.3 \pm 5.0$ & 0.001 \\
\hline $\mathrm{S}-25-\mathrm{OH}$ vitamin $\mathrm{D}(\mathrm{ng} / \mathrm{ml})$ & $21.4 \pm 11.4$ & $30.3 \pm 9.4$ & $<0.001$ \\
\hline S-intact PTH (pmol/l) & $5 \pm 2.2$ & $4 \pm 1.5$ & 0.026 \\
\hline S-calcium (mmol/l) & $2.3 \pm 0.1$ & $2.27 \pm 0.1$ & ns \\
\hline S-glycated hemoglobin $\mathrm{A}_{1 \mathrm{c}}\left(\mathrm{HbA}_{1 \mathrm{c}}\right)(\mathrm{mmol} / \mathrm{mol})$ & $52.2 \pm 15.7$ & $38.1 \pm 3.6$ & $<0.001$ \\
\hline S-fasting glucose $(\mathrm{mmol} / \mathrm{l})$ & $7.1 \pm 1.9$ & $5 \pm 0.5$ & $<0.001$ \\
\hline S-creatinine $(\mu \mathrm{mol} / \mathrm{l})$ & $67.99 \pm 13.6$ & $70.64 \pm 9.3$ & ns \\
\hline $\operatorname{GFR}\left(\mathrm{ml} / \mathrm{s} / 1.73 \mathrm{~m}^{2}\right)$ & $1.21 \pm 0.21$ & $1.17 \pm 0.13$ & ns \\
\hline
\end{tabular}

T2DM - type 2 diabetes mellitus; 25-OH D - 25-hydroxyvitamin D; BMI - body mass index; BMD - bone mineral density; LS - lumbar spine; S - serum; PTH - parathyroid hormone; GFR - Glomerular filtration rate

\section{Table 2A - Definition of vitamin $D$ status in T2DM postmenopausal women and controls without vitamin $D_{3}$ supplementation}

\begin{tabular}{lccc}
\hline & $\begin{array}{c}\text { Non-supplemented } \\
\text { T2DM women }\end{array}$ & $\begin{array}{c}\text { Non-supplemented } \\
\text { controls }\end{array}$ & P-value \\
\hline $\mathrm{N}$ & 55 & 20 & \\
Age (years) & $65.6 \pm 9$ & $64.0 \pm 5.9$ & $\mathrm{~ns}$ \\
BMl $\left(\mathrm{kg} / \mathrm{m}^{2}\right)$ & $31.7 \pm 7$ & $26.9 \pm 4.2$ & 0.003 \\
Total fat mass $(\mathrm{kg})$ & $34.5 \pm 11$ & $26.6 \pm 6.8$ & 0.029 \\
Total lean mass $(\mathrm{kg})$ & $48.2 \pm 7$ & $41.5 \pm 5.6$ & $\mathrm{~ns}$ \\
S-25-OH vitamin D $(\mathrm{ng} / \mathrm{ml})$ & $18.3 \pm 9.2$ & $27.99 \pm 8.6$ & $<0.001$ \\
Vitamin D deficiency $(<10 \mathrm{ng} / \mathrm{ml})$ & $10(18 \%)$ & $0(0 \%)$ & \\
Vitamin D insufficiency $(10-30 \mathrm{ng} / \mathrm{ml})$ & $39(71 \%)$ & $12(63 \%)$ & \\
Normal vitamin D values $(\geq 30 \mathrm{ng} / \mathrm{ml})$ & $6(11 \%)$ & $7(37 \%)$ & \\
\hline
\end{tabular}

T2DM - type 2 diabetes mellitus; 25-OH D - 25-hydroxyvitamin D; BMI - body mass index

hypovitaminosis $D$ had significantly lower serum calcium levels when compared to T2DM postmenopausal women with normal 25-OH D levels (Table 3).

In postmenopausal women with T2DM, the 25-OH D levels were not associated with $\mathrm{HbA1c}$, duration of diabetes, fasting glucose and PTH levels. Serum 25-OH D level negatively associated with total body fat mass $(p=0.005$, Figure $1 A)$, total body lean mass $(p=0.004$, Figure $1 B)$ and body mass index $(p=0.011$, Figure $2 A)$. 
Table 2B - Definition of vitamin D status in T2DM postmenopausal women and controls supplemented with vitamin $D_{3}$

\begin{tabular}{lccc}
\hline & $\begin{array}{c}\text { Supplemented } \\
\text { T2DM women }\end{array}$ & $\begin{array}{c}\text { Supplemented } \\
\text { controls }\end{array}$ & P-value \\
\hline $\mathrm{N}$ & 20 & 12 & \\
Age $($ years $)$ & $67.0 \pm 7$ & $64.08 \pm 5.9$ & $\mathrm{~ns}$ \\
$\mathrm{BMl}\left(\mathrm{kg} / \mathrm{m}^{2}\right)$ & $31.8 \pm 5.6$ & $23.88 \pm 2.7$ & $<0.001$ \\
Total fat mass $(\mathrm{kg})$ & $35.5 \pm 10.1$ & $21.7 \pm 3.7$ & 0.022 \\
Total lean mass $(\mathrm{kg})$ & $46.9 \pm 7.5$ & $40.4 \pm 2.4$ & $\mathrm{~ns}$ \\
S-25-OH vitamin D $(\mathrm{ng} / \mathrm{ml})$ & $29.8 \pm 12.8$ & $34.2 \pm 9.8$ & $\mathrm{~ns}$ \\
Vitamin D deficiency $(<10 \mathrm{ng} / \mathrm{ml})$ & $1(5 \%)$ & $0(0 \%)$ & \\
Vitamin D insufficiency $(10-30 \mathrm{ng} / \mathrm{ml})$ & $8(40 \%)$ & $5(42 \%)$ & \\
Normal vitamin D values $(\geq 30 \mathrm{ng} / \mathrm{ml})$ & $11(55 \%)$ & $7(58 \%)$ & \\
\hline
\end{tabular}

T2DM - type 2 diabetes mellitus; 25-OH D - 25-hydroxyvitamin D; BMI - body mass index

Table 3 - Glucose metabolism parameters and body composition indices in vitamin $D$ deficient T2DM postmenopausal women versus T2DM postmenopausal women with normal vitamin $D$ concentration

\begin{tabular}{lccc}
\hline & $\begin{array}{c}\text { Normal } \\
\text { vitamin } D \\
\text { concentration }\end{array}$ & $\begin{array}{c}\text { Vitamin D } \\
\text { deficiency/ } \\
\text { insufficiency }\end{array}$ & P-value \\
\hline $\mathrm{N}$ & 17 & 58 & \\
Age (years) & $69.9 \pm 8.4$ & $64.9 \pm 8.3$ & 0.036 \\
Years after menopause (years) & $20.1 \pm 8.4$ & $15.5 \pm 8.1$ & 0.050 \\
BMl $\left(\mathrm{kg} / \mathrm{m}^{2}\right)$ & $29.1 \pm 4.1$ & $32.6 \pm 7.1$ & $\mathrm{~ns}$ \\
Total fat mass $(\mathrm{kg})$ & $28.6 \pm 9.9$ & $36 \pm 11.0$ & $\mathrm{~ns}$ \\
Total lean mass $(\mathrm{kg})$ & $44.4 \pm 8.9$ & $48.6 \pm 6.9$ & $\mathrm{~ns}$ \\
S-calcium (mmol/l) & $2.35 \pm 0.1$ & $2.28 \pm 0.1$ & 0.005 \\
S-25-OH vitamin D (ng/ml) & $38 \pm 6.6$ & $16.5 \pm 7.1$ & $<0.001$ \\
S-intact PTH (pmol/l) & $4.8 \pm 1.6$ & $5.1 \pm 2.3$ & $\mathrm{~ns}$ \\
S-fasting glucose $(\mathrm{mmol} / \mathrm{l})$ & $7.5 \pm 2.3$ & $7 \pm 1.7$ & $\mathrm{~ns}$ \\
T2DM duration (years) & $5.1 \pm 6.2$ & $6.6 \pm 6.7$ & $\mathrm{~ns}$ \\
S-glycated hemoglobin A $1 \mathrm{c}\left(\mathrm{HbA}_{1 \mathrm{c}}\right)(\mathrm{mmol} / \mathrm{mol})$ & $53.1 \pm 11.9$ & $51.9 \pm 16.6$ & $\mathrm{~ns}$ \\
\hline
\end{tabular}

T2DM - type 2 diabetes mellitus; 25-OH D - 25-hydroxyvitamin D; BMI - body mass index; PTH - parathyroid hormone

Furthermore, the serum 25-OH D level was negatively associated with total proximal femur BMD $(p=0.014)$ in T2DM patients. Total proximal femur BMD positively associated with BMI $(p<0.001)$, total body fat mass $(p<0.001)$ and also total body lean mass $(p<0.001)$ in T2DM patients. These associations persisted after adjustment for age and duration of T2DM. In a control group, the 25-OH D levels were associated with body mass index $(\mathrm{P}=0.020$, Figure $2 \mathrm{~B})$.

The PTH levels were not associated with $\mathrm{HbA1c}$, duration of diabetes, fasting glucose, BMI, as well as body composition indices in T2DM postmenopausal women. 

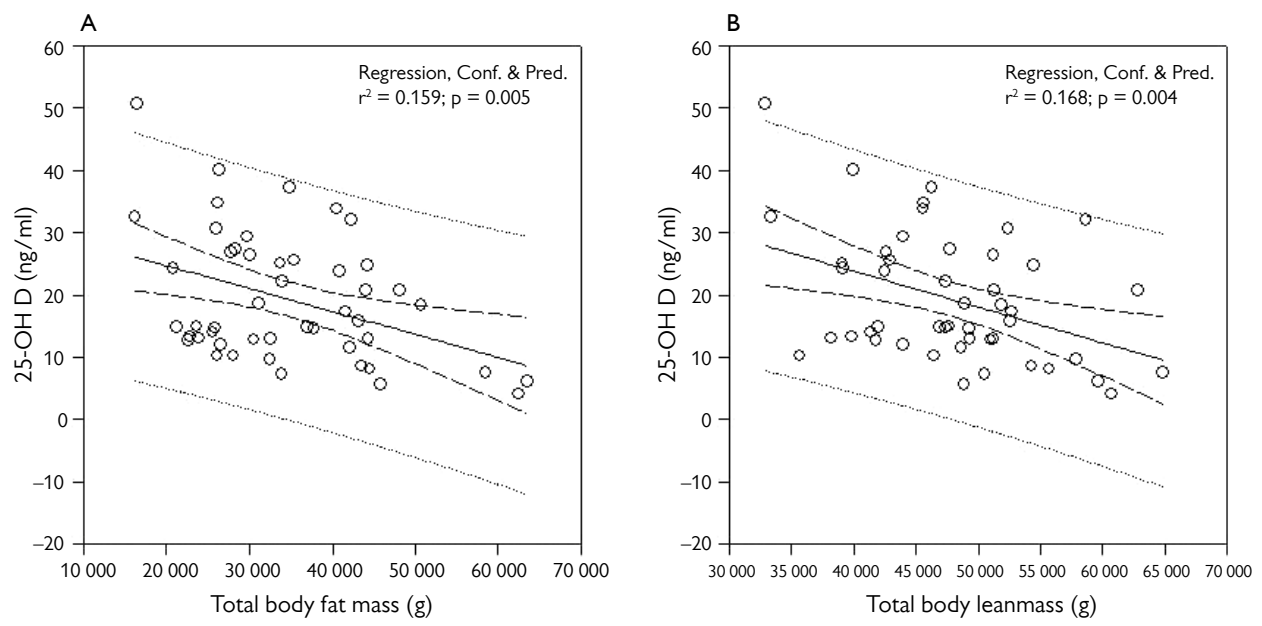

Figure $1 A$ and $B$ - Relationship between total body fat mass $(A)$ or total body lean mass (B) and 25-hydroxyvitamin $D(25-O H D)$ in type 2 diabetes mellitus (T2DM) patients. Dotted lines: prediction intervals.
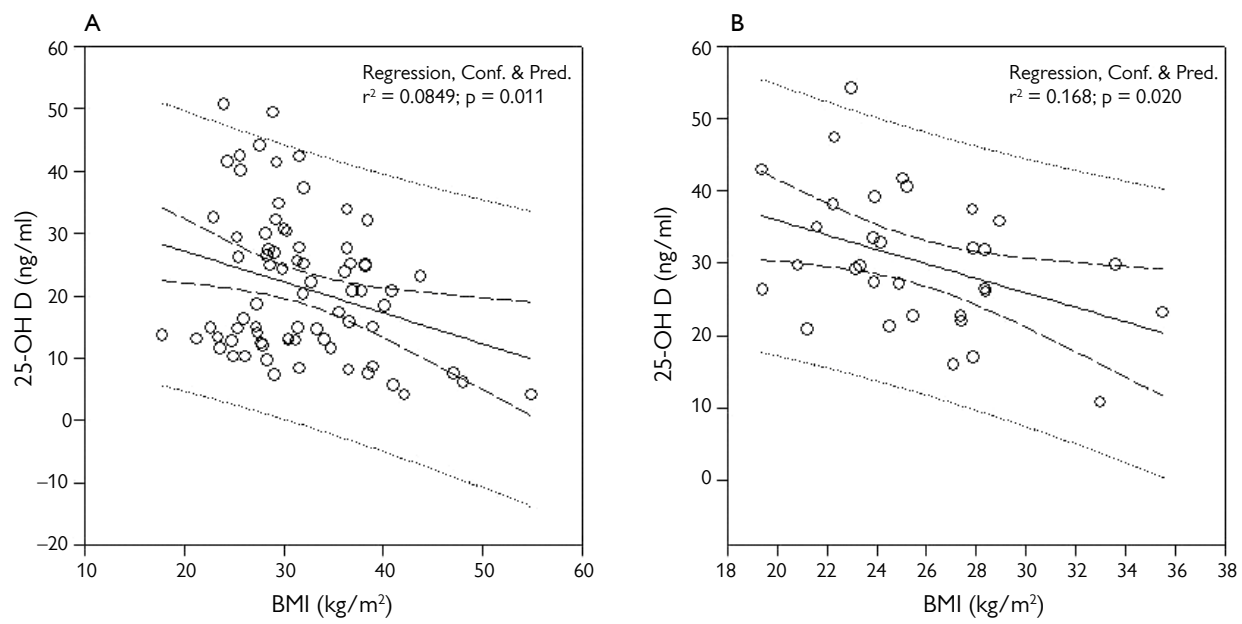

Figure $2 A$ and $B$ - Relationship between body mass index (BMI) and 25-hydroxyvitamin $D(25-\mathrm{OH} D)$ in type 2 diabetes mellitus (T2DM) patients (A) and controls (B). Dotted lines: prediction intervals.

No association between PTH and BMI or body composition indices was found also in the control group.

\section{Discussion}

\section{Prevalence of hypovitaminosis $D$}

Vitamin D deficiency is recognized as a worldwide issue (Personne et al., 2013).

The estimated prevalence of vitamin $D$ insufficiency in the general population is as high as 50 to $80 \%$ (Holick et al., 2005; Ginde et al., 2009). The reported prevalence 
of vitamin $D$ deficiency or insufficiency in patients with T2DM depends on the threshold used to define vitamin $D$ deficiency or insufficiency. In our study, vitamin $D$ insufficiency was defined as a $25-\mathrm{OH} D$ level $<30 \mathrm{ng} / \mathrm{ml}$, which is in accordance with the recommendation of International Osteoporosis Foundation (IOF). Our data showed higher prevalence of hypovitaminosis $D$ in non-supplemented postmenopausal women with T2DM than in non-diabetic controls ( $89 \%$ vs. $63 \%$ ). These data are consistent with a previously published study, in which $74.6 \%$ of patients with T2DM had hypovitaminosis D (Miñambres et al., 2014). In another study, the prevalence of low serum $25-\mathrm{OH} \mathrm{D}(<50 \mathrm{nmol} / \mathrm{l})$ was more common in diabetics compared with controls ( $83 \%$ vs. $70 \%$; $p=0.07$ ) (Tahrani et al., 2010). In a recent study the prevalence of hypovitaminosis $D$ was higher in diabetic patients than in control subjects ( $90 \%$ vs. $83 \%$; $p<0.01$ ) (Muscogiuri et al., 2016).

\section{Hypovitaminosis $D$ and body composition indices}

Several studies have shown that patients with hypovitaminosis D had higher prevalence of overweight or obesity when compared to patients with normal 25-OH D status (Miñambres et al., 2014). Furthermore, obesity is associated with low serum 25-OH D levels (González-Molero et al., 2013; Vimaleswaran et al., 2013; Shantavasinkul et al., 2015). In our study, we found a significant negative association between 25-OH D levels and BMI (Figure 2A) and total body fat mass (Figure 1A). The exact underlying mechanism of this relationship is not clearly understood and several mechanisms have been hypothesized. One of the most discussed mechanisms is explained by low bioavailability of vitamin $D$ when high content of body fat acts as a reservoir for lipid soluble vitamin $D$ and increases its sequestration (Wortsman et al., 2000). Furthermore, the synthesis of 25-OH D may be decreased in obese subjects because of hepatic steatosis (Targher et al., 2007; Dasarathy et al., 2014). In addition, low sun exposure and limited cutaneous vitamin $D$ synthesis in obese patients may also play a role (Florez et al., 2007).

Moreover, we have found a significant negative association between 25-OH D levels and total body lean mass. It has been reported in animal studies, that 25-OH D stores are distributed in the body fat and also in muscle tissue (Jakobsen et al., 2007). Therefore, it is tempting to speculate that muscle can create another reservoir of vitamin $D$ also in humans.

In addition, our data showed no association between PTH levels and total body fat mass or BMI.These results are in contrast with previously reported data in nondiabetic subjects showing that fat mass is a significant independent determinant of serum PTH levels (Bolland et al., 2006). We suggest that this discrepancy may be caused by high variables of PTH levels.

\section{5-OH D levels vs. PTH and bone measures}

In our study, postmenopausal women with T2DM had significantly higher PTH levels when compared with non-diabetic control subjects. In the present study, 
the intact-PTH level was within the normal range and 25-OH D levels were not associated with PTH levels.

Vitamin $D$ deficiency is more common in diabetic patients with nephropathy (Usluogullari et al., 2015) which is linked to higher PTH levels. In our study, T2DM patients had no medical history of diabetic nephropathy.

However, it has been suggested, that PTH is suppressed at a lower serum 25-OH D level in obese women compared to the general population (Shapses et al., 2013). It is possible that there may be a different set point for the calcium PTH relationship in the obese, as demonstrated in a calcium-citrate clamp that showed an exaggerated PTH response to hypocalcemia as compared to normal subjects (Hultin et al., 2010; Cipriani et al., 2014). Moreover, while many subjects with hypovitaminosis D could have PTH within the "normal" reference range, they may have "functional hyperparathyroidism" (Souberbielle et al., 2003).

Vitamin $D$ deficiency is known to be related with increased risk of fracture (Holvik et al., 2013) and positively associated with low BMD (Sadat-Ali et al., 2011). However, we have found a significant negative association between 25-OH D levels and total proximal femur BMD, but not between lumbar spine BMD and 25-OH D. The mechanism of this phenomenon might be explained by higher weight of diabetic patients, which causes the greater skeletal mechanical loading resulting in an increase in total proximal femur BMD. We have identified a significant positive association between total proximal femur BMD and BMI in T2DM patients. In harmony with these results, we have found significantly higher total proximal femur BMD in T2DM patients when compared to the control group. However, recent studies suggest that poor cortical bone quality is responsible for fragility fractures in postmenopausal diabetic women. Further techniques, such as peripheral quantitative computed tomography that enables the separate analysis of both trabecular and cortical bone compartment, may provide a better insight into the cortical bone in T2DM patients.

\section{5-OH D level and glucose metabolism}

Vitamin $D$ deficiency is thought to influence the insulin resistance and the pathogenesis of T2DM by affecting either insulin sensitivity, $\beta$-cell function, or both (Chiu et al., 2004; Deleskog et al., 2012). However, we have found no significant difference in fasting glucose, glycated hemoglobin or duration of diabetes in group of T2DM patients with hypovitaminosis $D$ versus patients with normal vitamin $D$ status (Table 3). The design of our study was cross-sectional, not focused on monitoring the impact of vitamin $D$ supplementation itself on glycemic control. Therefore, we did not measure the glycemic parameters before and after vitamin $D$ supplementation. We have found no association between $25-\mathrm{OH}$ D, PTH or body mass indices with fasting glycemia, $\mathrm{HbA} 1 \mathrm{c}$ or duration of diabetes. Although epidemiological studies and meta-analysis showed an association between low serum 25-OH D and impaired glycaemia (Pittas et al., 2010; Mitri et al., 2011), 
vitamin D intervention trials have had inconsistent results (Avenell et al., 2009; Von Hurst et al., 2010; Harris et al., 2011; Davidson et al., 2013). Therefore, it is uncertain whether vitamin $D$ deficiency and poor glycemic control are causally interrelated or they represent two independent features of T2DM. The high prevalence of hypovitaminosis $D$ in postmenopausal women with T2DM highlights the need for prospective studies in order to evaluate the impact of vitamin $D$ supplementation on glucose metabolism.

\section{Adequate dose of vitamin $D$}

In our cross-sectional study, T2DM patients taking low doses of vitamin $\mathrm{D}_{3}$ supplements (500-1000 IU per day) had higher 25-OH D level when compared to non-supplemented group of T2DM patients. Nevertheless, $45 \%$ of supplemented T2DM patients still had hypovitaminosis D. These data suggest that low dose vitamin $D$ supplementation may be inadequate in T2DM postmenopausal women. Recent meta-analysis have demonstrated that serum $25-\mathrm{OH}$ D concentrations less than or equal to $30 \mathrm{ng} / \mathrm{ml}$ were associated with higher all-cause mortality than concentrations greater than $30 \mathrm{ng} / \mathrm{ml}(p<0.01)$ (Garland et al., 2014). A meta-analysis of randomized controlled trials (non DM population) showed that supplemental vitamin $D$ of $700-1000 \mathrm{IU} /$ day reduced the risk of falls by $19 \%$ whereas achieved serum $25-\mathrm{OH} \mathrm{D}$ concentrations of $60 \mathrm{nmol} / \mathrm{l}$ or more resulted in a $23 \%$ fall reduction. No benefit was observed with lower supplemental doses or lower serum 25-OH D concentrations (Bischoff-Ferrari et al., 2009). To our knowledge, the studies dealing with the evaluation of the effect of vitamin D supplementation on BMD or risk of falls in diabetic population are missing. Based on data of from Bischoff-Ferrari and others on non-diabetic population, the serum concentrations of 25-OH D should be $75 \mathrm{nmol} / \mathrm{l}$ or more (Bischoff-Ferrari, 2007). Growing evidence suggest larger doses of vitamin D (equivalent to $2000 \mathrm{IU}$ to $10000 \mathrm{IU}$ daily) are required to optimise vitamin D status (Vieth et al., 2007). Furthermore, the question what dose of vitamin $D$ should be used in obese patients to replete vitamin $D$ stores and how to maintain normal 25-OH D levels after repletion remains unresolved (Cipriani et al., 2014).

\section{Limitation of the study}

In this cross-sectional study, we did not evaluate the duration of vitamin $D_{3}$ supplementation and patient's compliance with this supplementation. Moreover, due to low number of patients we could not validly assess the effect the seasonal fluctuations of 25-OH D levels and the effect of vitamin $D_{3}$ supplementation on glucose and bone metabolism parameters. Nevertheless, high prevalence of hypovitaminosis $D$ (also in supplemented group) underscores the need for prospective studies to evaluate the impact of vitamin $D$ supplementation on bone, muscle and glucose metabolism. 


\section{Conclusion}

Our results demonstrate the high prevalence of low 25-OH D levels (below $30 \mathrm{ng} / \mathrm{ml}$ ), affecting $89 \%$ of non-supplemented postmenopausal women with T2DM. Moreover, up to $45 \%$ of supplemented T2DM patients still have hypovitaminosis D. Obesity is a risk factor for vitamin $D$ insufficiency in postmenopausal women with T2DM. Further especially prospective studies determining the adequate and safe dose of vitamin $D$, which significantly reduces the risk of fracture and affects the insulin resistance in T2DM patients are warranted.

\section{References}

Avenell, A., Cook, J. A., MacLennan, G. S., McPherson, G. C.; RECORD trial group (2009) Vitamin D supplementation and type 2 diabetes: a substudy of a randomised placebo-controlled trial in older people (RECORD trial, ISRCTN 51647438). Age Ageing 38(5), 606-609.

Badawi, A., Sayegh, S., Sadoun, E., Al-Thani, M., Arora, P., Haddad, P. S. (2014) Relationship between insulin resistance and plasma vitamin D in adults. Diabetes Metab. Syndr. Obes. 7, 297-303.

Bischoff-Ferrari, H.A. (2007) How to select the doses of vitamin D in the management of osteoporosis. Osteoporos. Int. 18(4), 401-407.

Bischoff-Ferrari, H. A., Dawson-Hughes, B., Willett, W. C., Staehelin, H. B., Bazemore, M. G., Zee, R.Y., Wong, J. B. (2004) Effect of vitamin D on falls: a meta-analysis. JAMA 291(16), 1999-2006.

Bischoff-Ferrari, H. A., Dawson-Hughes, B., Staehelin, H. B., Orav, J. E., Stuck, A. E., Theiler, R., Wong, J. B., Egli, A., Kiel, D. P., Henschkowski, J. (2009) Fall prevention with supplemental and active forms of vitamin D: a meta-analysis of randomised controlled trials. BMJ 339, b3692.

Bolland, M. J., Grey, A. B., Ames, R.W., Horne, A. M., Gamble, G. D., Reid, I. R. (2006) Fat mass is an important predictor of parathyroid hormone levels in postmenopausal women. Bone 38(3), 317-321.

Chiu, K. C., Chu, A., Go, V. L., Saad, M. F. (2004) Hypovitaminosis D is associated with insulin resistance and beta cell dysfunction. Am. J. Clin. Nutr. 79(5), 820-825.

Cipriani, C., Pepe, J., Piemonte, S., Colangelo, L., Cilli, M., Minisola, S. (2014) Vitamin D and its relationship with obesity and muscle. Int. J. Endocrinol. 2014, 841248.

Dasarathy, J., Periyalwar, P., Allampati, S., Bhinder, V., Hawkins, C., Brandt, P., Khiyami, A., McCullough, A. J., Dasarathy, S. (2014) Hypovitaminosis D is associated with increased whole body fat mass and greater severity of non-alcoholic fatty liver disease. Liver Int. 34(6), e118-e127.

Davidson, M. B., Duran, P., Lee, M. L., Friedman, T. C. (2013) High-dose vitamin D supplementation in people with prediabetes and hypovitaminosis D. Diabetes Care 36(2), 260-266.

Deleskog, A., Hilding, A., Brismar, K., Hamsten, A., Efendic, S., Östenson, C. G. (2012) Low serum 25-hydroxyvitamin $\mathrm{D}$ level predicts progression to type 2 diabetes in individuals with prediabetes but not with normal glucose tolerance. Diabetologia 55(6), 1668-1678.

Delvin, E. E. (2011) Importance of vitamin D in insulin resistance. Bull. Acad. Natl. Med. 195(4-5), 1091-1102. (in French)

Florez, H., Martinez, R., Chacra, W., Strickman-Stein, N., Levis, S. (2007) Outdoor exercise reduces the risk of hypovitaminosis D in the obese. J. Steroid Biochem. Mol. Biol. 103(3-5), 679-681.

Garland, C. F., Kim, J. J., Mohr, S. B., Gorham, E. D., Grant, W. B., Giovannucci, E. L., Baggerly, L., Hofflich, H., Ramsdell, J.W., Zeng, K., Heaney, R. P. (2014) Meta-analysis of all-cause mortality according to serum 25-hydroxyvitamin D. Am. J. Public Health 104(8), 43-50.

Ginde, A. A., Liu, M. C., Camargo, C. A. Jr. (2009) Demographic differences and trends of vitamin D insufficiency in the US population, 1988-2004. Arch. Intern. Med. 169(6), 626-632. 
González-Molero, I., Rojo-Martínez, G., Morcillo, S., Gutierrez, C., Rubio, E., Pérez-Valero, V., Esteva, I., Ruiz de Adana, M. S., Almaraz, M. C., Colomo, N., Olveira, G., Soriguer, F. (2013) Hypovitaminosis D and incidence of obesity: a prospective study. Eur. J. Clin. Nutr. 67(6), 680-682.

Harris, R. A., Pedersen-White, J., Guo, D. H., Stallmann-Jorgensen, I. S., Keeton, D., Huang,Y., Shah, Y., Zhu, H., Dong, Y. (2011) Vitamin D3 supplementation for 16 weeks improves flow-mediated dilation in overweight African-American adults. Am. J. Hypertens. 24(5), 557-562.

Holick, M. F., Siris, E. S., Binkley, N., Beard, M. K., Khan, A., Katzer, J.T., Petruschke, R. A., Chen, E., de Papp, A. E. (2005) Prevalence of vitamin D inadequacy among postmenopausal North American women receiving osteoporosis therapy. J. Clin. Endocrinol. Metab. 90(6), 3215-3224.

Holvik, K., Ahmed, L. A., Forsmo, S., Gjesdal, C. G., Grimnes, G., Samuelsen, S. O., Schei, B., Blomhoff, R., Tell, G. S., Meyer, H. E. (2013) Low serum levels of 25-hydroxyvitamin D predict hip fracture in the elderly: a NOREPOS study. J. Clin. Endocrinol. Metab. 98(8), 3341-3350.

Hultin, H., Edfeldt, K., Sundbom, M., Hellman, P. (2010) Left-shifted relation between calcium and parathyroid hormone in obesity. J. Clin. Endocrinol. Metab. 95(8), 3973-3981.

Jakobsen, H., Maribo, A., Bysted, H. M., Sommer, O. H. (2007) 25-hydroxyvitamin D3 affects vitamin D status similar to vitamin D3 in pigs - But the meat produced has a lower content of vitamin D. Br. J. Nutr. 98 , 908-913.

Janghorbani, M., Van Dam, R. M.,Willett, W. C., Hu, F. B. (2007) Systematic review of type 1 and type 2 diabetes mellitus and risk of fracture. Am. J. Epidemiol. 166(5), 495-505.

Martinez-Laguna, D., Tebe, C., Javaid, M. K., Nogues, X., Arden, N. K., Cooper, C., Diez-Perez, A., Prieto-Alhambra, D. (2015) Incident type 2 diabetes and hip fracture risk: a population-based matched cohort study. Osteoporos. Int. 26(2), 827-833.

Miñambres, I., Sánchez-Quesada, J. L., Vinagre, I., Sánchez-Hernández, J., Urgell, E., de Leiva, A., Pérez, A. (2014) Hypovitaminosis $D$ in type 2 diabetes: relation with features of the metabolic syndrome and glycemic control. Endocr. Res. 40(3), 160-165.

Mitri, J., Muraru, M. D., Pittas, A. G. (2011) Vitamin D and type 2 diabetes: a systematic review. Eur. J. Clin. Nutr. 65(9), 1005-1015.

Muscogiuri, G., Nuzzo, V., Gatti, A., Zuccoli, A., Savastano, S., Di Somma, C., Pivonello, R., Orio, F., Colao, A. (2016) Hypovitaminosis D: a novel risk factor for coronary heart disease in type 2 diabetes? Endocrine 51(2), 268-273.

Norman, A.W., Frankel, J. B., Heldt, A. M., Grodsky, G. M. (1980) Vitamin D deficiency inhibits pancreatic secretion of insulin. Science 209(4458), 823-825.

Penckofer, S., Kouba, J., Wallis, D. E., Emanuele, M. A. (2008) Vitamin D and diabetes: let the sunshine in. Diabetes Educ. 34(6), 939-940, 942, 944.

Personne, V., Partouche, H., Souberbielle, J. C. (2013) Vitamin D insufficiency and deficiency: epidemiology, measurement, prevention and treatment. Presse Med. 42(10), 1334-1342.

Pittas, A. G., Chung, M., Trikalinos, T., Mitri, J., Brendel, M., Patel, K., Lichtenstein, A. H., Lau, J., Balk, E. M. (2010) Systematic review:Vitamin D and cardiometabolic outcomes. Ann. Intern. Med. 152(5), 307-314.

Plotnikoff, G. A., Quigley, J. M. (2003) Prevalence of severe hypovitaminosis D in patients with persistent, nonspecific musculoskeletal pain. Mayo Clin. Proc. 78(12), 1463-1470.

Sadat-Ali, M., Al Elq, A. H., Al-Turki, H. A., Al-Mulhim, F. A., Al-Ali, A. K. (2011) Influence of vitamin D levels on bone mineral density and osteoporosis. Ann. Saudi Med. 31(6), 602-608.

Scragg, R., Sowers, M., Bell, C. (2004) Third national health and nutrition examination survey: Serum 25 -hydroxyvitamin $D$, diabetes, and ethnicity in the third national health and nutrition examination survey. Diabetes Care 27(12), 2813-2818.

Raška I. Jr.; Rašková M.; Zikán V.; Škrha J. 
Shantavasinkul, P. C., Phanachet, P., Puchaiwattananon, O., Chailurkit, L. O., Lepananon, T., Chanprasertyotin, S., Ongphiphadhanakul, B., Warodomwichit, D. (2015) Vitamin D status is a determinant of skeletal muscle mass in obesity according to body fat percentage. Nutrition 31(6), 801-806.

Shapses, S. A., Lee, E. J., Sukumar, D., Durazo-Arvizu, R., Schneider, S. H. (2013) The effect of obesity on the relationship between serum parathyroid hormone and 25-hydroxyvitamin D in women. J. Clin. Endocrinol. Metab. 98(5), E886-E890.

Souberbielle, J. C., Lawson-Body, E., Hammadi, B., Sarfati, E., Kahan, A., Cormier, C. (2003) The use in clinical practice of parathyroid hormone normative values established in vitamin D-sufficient subjects. J. Clin. Endocrinol. Metab. 88(8), 3501-3504.

Tahrani, A. A., Ball, A., Shepherd, L., Rahim, A., Jones, A. F., Bates, A. (2010) The prevalence of vitamin D abnormalities in South Asians with type 2 diabetes mellitus in the UK. Int. J. Clin. Pract. 64(3), 351-355.

Targher, G., Bertolini, L., Scala, L., Cigolini, M., Zenari, L., Falezza, G., Arcaro, G. (2007) Associations between serum 25-hydroxyvitamin D3 concentrations and liver histology in patients with non-alcoholic fatty liver disease. Nutr. Metab. Cardiovasc. Dis. 17(7), 517-524.

Usluogullari, C.A., Balkan, F., Caner, S., Ucler, R., Kaya, C., Ersoy, R., Cakir, B. (2015) The relationship between microvascular complications and vitamin D deficiency in type 2 diabetes mellitus. BMC Endocr. Disord. 15, 33.

Vestergaard, P. (2007) Discrepancies in bone mineral density and fracture risk in patients with type 1 and type 2 diabetes - a meta-analysis. Osteoporos. Int. 18(4), 427-444.

Vieth, R., Bischoff-Ferrari, H., Boucher, B. J., Dawson-Hughes, B., Garland, C. F., Heaney, R. P., Holick, M. F., Hollis, B.W., Lamberg-Allardt, C., McGrath, J. J., Norman, A. W., Scragg, R., Whiting, S. J., Willett, W. C., Zittermann, A. (2007) The urgent need to recommend an intake of vitamin $D$ that is effective. Am. J. Clin. Nutr. 85(3), 649-650.

Vimaleswaran, K. S., Berry, D. J., Lu, C., Tikkanen, E., Pilz, S., Hiraki, L. T., Cooper, J. D., Dastani, Z., Li, R., Houston, D. K., Wood, A. R., Michaëlsson, K., Vandenput, L., Zgaga, L., Yerges-Armstrong, L. M., McCarthy, M. I., Dupuis, J., Kaakinen, M., Kleber, M. E., Jameson, K., Arden, N., Raitakari, O., Viikari, J., Lohman, K. K., Ferrucci, L., Melhus, H., Ingelsson, E., Byberg, L., Lind, L., Lorentzon, M., Salomaa, V., Campbell, H., Dunlop, M., Mitchell, B. D., Herzig, K. H., Pouta, A., Hartikainen, A. L.; Genetic Investigation of Anthropometric Traits-GIANT Consortium, Streeten, E. A., Theodoratou, E., Jula, A., Wareham, N. J., Ohlsson, C., Frayling, T. M., Kritchevsky, S. B., Spector, T. D., Richards, J. B., Lehtimäki, T., Ouwehand, W. H., Kraft, P., Cooper, C., März, W., Power, C., Loos, R. J., Wang, T. J., Järvelin, M. R., Whittaker, J. C., Hingorani, A. D., Hyppönenm, E. (2013) Causal relationship between obesity and vitamin D status: bi-directional Mendelian randomization analysis of multiple cohorts. PLoS Med. 10(2), e1001383.

Von Hurst, P. R., Stonehouse, W., Coad, J. (2010) Vitamin D supplementation reduces insulin resistance in South Asian women living in New Zealand who are insulin resistant and vitamin D deficient a randomised, placebo-controlled trial. Br. J. Nutr. 103(4), 549-555.

Wolden-Kirk, H., Overbergh, L., Christesen, H. T., Brusgaard, K., Mathieu, C. (2011) Vitamin D and diabetes: its importance for beta cell and immune function. Mol. Cell. Endocrinol. 347(1-2), 106-120.

Wortsman, J., Matsuoka, L. Y., Chen, T. C., Lu, Z., Holick, M. F. (2000) Decreased bioavailability of vitamin D in obesity. Am. J. Clin. Nutr. 72(3), 690-693. 